\title{
Coverage of lodized Salt and Associated Factors at Household Level in Goba Town, Bale Zone, South East Ethiopia, 2015
}

\author{
Abdurrahman Kalu Tololu" , , Fentie Ambaw Getahun², Dereje Birhanu Abitew ${ }^{2}$ \\ ${ }^{1}$ Department of Public Health, Goba Referral Hospital, Madawalabu University, Bale Goba, Ethiopia \\ ${ }^{2}$ Department of Public Health, College of Medicine \& Health Science, Bahir Dar University, Bahir Dar, Ethiopia
}

\section{Email address:}

abdurehmankelu900@gmail.com (A. K. Tololu), fentiegetahun@gmail.com (F. A. Getahun), firedereje@gmail.com (D. B. Abitew)

${ }^{*}$ Corresponding author

\section{To cite this article:}

Abdurrahman Kalu Tololu, Fentie Ambaw Getahun, Dereje Birhanu Abitew. Coverage of Iodized Salt and Associated Factors at Household Level in Goba Town, Bale Zone, South East Ethiopia, 2015. Science Journal of Public Health. Vol. 4, No. 4, 2016, pp. $346-351$. doi: 10.11648/j.sjph.20160404.22

Received: September 28, 2015; Accepted: October 27, 2015; Published: July 11, 2016

\begin{abstract}
Background: Iodine Deficiency Disorder is one of the biggest worldwide public health problems of today. Fortification of salt with iodine is recognized as the most simple and cost effective strategy to achieve recommended daily intake of iodine. Hence this study wanted to assess coverage of adequately iodized salt $\&$ associated factors at household level in Goba town. Methods: Community based cross-sectional survey conducted among 598 households using concurrent qualitative \& quantitative method in Goba town, South East Ethiopia from August 1-30, 2013. Data were collected by trained diploma nurses supervised by BSC nurses. Interviewer administered questionnaire \& rapid field test kits were used to collect the data. Data were cleaned, coded \& entered in to EPI Info and exported to SPSS for analysis. Data were summarized in tables \& charts. Variables having $\mathrm{p}$ value $\leq 0.2$ in univariate analysis were entered into multivariate logistic regression to test association between the outcome and predictable variables at $\mathrm{p}$ value $\leq 0.05$. Results: From a total of 596 households included in the study, only $30 \%$ of the households were covered by adequately iodized salt. Regarding the associated factors, about coverage of adequately iodized salt, not exposing to sunlight, purchasing from supermarkets or big shops \& perceived cheap were found to be statistically significant with AOR $(95 \% \mathrm{CI})=2.20(1.31,3.60), 1.91(1.10,3.34), 1.70(1.10,2.0)$ respectively. Conclusion: Coverage of adequately iodized salt at household level was low $(30 \%)$ in Goba town. The main associated factors were not exposing to sun light, purchased from big shop or supermarket \& perceived cheap. Households' should be educated about proper handling of iodized salt at household level.
\end{abstract}

Keywords: Coverage, Iodized Salt, Associated Factors

\section{Background}

Iodine presents in the body in a minute amounts, mainly in the thyroid gland. Its main role is in the synthesis of thyroid hormones. When requirements are not met, thyroid hormone synthesis is impaired, resulting in hypothyroidism and a series of functional and developmental abnormalities grouped under the heading of "Iodine Deficiency Disorders [1]. Failure to have adequate iodine leads to insufficient production of thyroid hormones, which affects different parts of the body, particularly muscle, heart, liver, kidney, and the developing brain. Inadequate hormone production adversely affects these tissues resulting in the disease states known collectively as iodine deficiency disorders [2]. The WHO/UNICEF/ICCIDD recommends that iodine concentration in salt at the point of production should be within the range of $20-40 \mathrm{mg}$ of iodine per $\mathrm{kg}$ of salt (i.e. $20-40$ ppm of iodine) in order to Provide $150 \mathrm{mcg}$ of iodine per person per day [3]. The actual availability of iodine in the iodized salt at the consumer level can vary over a wide range as a result of variability in the amount of iodine added during the iodization process, uneven distribution of iodine in the iodized salt, the extent of loss iodine due to salt impurities, packaging \& environmental conditions during storage $\&$ transportation, loss of iodine due to washing $\&$ cooking process in the household, $\&$ the 
availability of non-iodized salt from unconventional marketing sources [4]. Iodine deficiency is a major global public health problem, particularly for young children \& pregnant women. The most serious effect of iodine deficiency is mental retardation. It is one of the world's major causes of preventable cognitive impairment, posing a threat to social \& economic development of countries [5].

\section{Methods \& Materials}

\subsection{Study Design, Period \& Setting}

Community based cross-sectional quantitative study were used. The study was conducted from August 1 -30, 2013 in Goba town which is located in the southeastern part of the country along Addis Ababa Goba road which is 445 via Assela. Goba is one of the highland towns situated at the foot of Bale Mountain chain which is characterized by rugged terrain landscape. The relief of Goba town was found between 2510 and 2800 meters above sea level $\&$ the average elevation being about 2655 meters above sea level. The total populations were 41,328 of which male accounts $19,643(47.5 \%)$, \& female being 21,685 (52.5\%). The largest proportion of population of Goba town were Orthodox (71.9\%), Muslim (21\%), followed by others $(7.1 \%)[24]$.

\subsection{Study Population, Sample Size \& Sampling Procedure}

The study population was selected households in the selected kebeles in Goba town. Member of households whose age was $18 \&$ above \& more responsible in purchasing food items and mostly involved in food preparation were interviewed. The sample size was determined by using formula for estimating single population proportion.

$$
n=\frac{(Z \alpha / 2)^{2} * \mathrm{p}(1-\mathrm{p})}{d^{2}}
$$

The following assumptions were used to obtain the optimum sample size.

$\mathrm{P}=$ proportion of households consuming adequately iodized salt $(15 \%)$ [10]. $\mathrm{Z}$ statistic $=1.96, \mathrm{~d}=$ the maximum allowable error taken (3\%), \& non-response rate $10 \%$ giving final sample size 598 households. After identifying the center of the town (market area) the starting point for sampling, the east direction were identified randomly \& the first household number was selected by using lottery method $\&$ then by systematic random sampling technique every $14^{\text {th }}$ household was visited to get the required number of study subjects in each kebeles.

\subsection{Data Collection Procedures}

Data were collected using pretested interviewer administered structured questionnaires on respondents: educational level, occupation, availability of iodized salt, monthly household income, environmental factors, knowledge, attitude, \& perception on price of iodized salt. In addition to the training given to the data collectors, the questionnaire was pretested 5 days before the actual data collection days in one of the kebeles in Robe town which is 12 kilometers away from Goba town on $5 \%$ of the total sample size. Moreover data collection \& completeness of filled questionnaire was checked in the field. To assess the coverage of iodized salt at household level, a teaspoonful of salt sample used for cooking was tested by using rapid test kit obtained from UNICEF \& Micronutrient Initiative. Six trained diploma nurses and two supervisors were recruited during data collection.

\subsection{Data Management and Analysis}

After data collection, each questionnaire was checked for completeness and consistency by supervisors. Data were cleaned using computer software program \& entered in to epi-info version 3.5.1 \& exported to SPSS version 20.0 for analysis. Data summarized with tables \& charts. Variables having $p$-value $\leq 0.2$ in the univariate analysis were entered in to multivariate logistic regression models to control confounding factors. Then odds ratio at 95\% confidence interval was used to show association between dependent and independent variables. $\mathrm{P}$ value of $\leq 0.05$ considered statistically significant in the multivariate analysis. Participants who respond above mean for seven knowledge questions were considered to have sufficient knowledge \& who respond below the mean for seven knowledge questions were considered to have insufficient knowledge. Participants who respond above the mean for seven attitudinal questions were considered to have favorable attitude \& who respond below the mean for seven attitudinal questions were considered to have unfavorable attitude. Adequately iodized salt at household level: is defined as salt sample which had $\geq 15$ parts per million (PPM) of iodine during salt sample test.

Data quality assurance was done during questionnaire designing, data collection \& data entry. Questionnaire was logically sequenced, free of scientific terms, non-leading and pretested. Data was checked for its consistency and completeness every day on the sites by supervisors.

\subsection{Ethical Considerations}

Ethical clearance was obtained from the Ethical Committee of Bahir Dar University, College of Medicine \& Health Science. Letters of permission was gained from Oromia Regional Health Bureau, Bale Zone Health Bureau and Goba Town Health Office. Informed consent was obtained from participants involved in the study, from head of household \& study participants. The participants were allowed to consider their participation and given the opportunity to withdraw from the study at any point in the course of the study if they wished to do so. Participants' name or personal identifier was not included in the written questionnaires to ensure participants' confidentiality Health education on the importance and source of iodized salt and proper handling of it at household level was given by the data collectors for households after data collection.

\section{Results}

Socio demographic characteristic of the respondents: A 
total of 596 households participated in the study with response rate of $99.7 \%$. Among those 555 (93.1\%) were females, $196(32.9 \%)$ of respondents lies within $25-34$ years of age category, 411 (69\%) married, 445 (74.7\%) Christian in religion, 316 (53\%) Oromo by ethnicity while, $186(31.2 \%)$ had at least above secondary school in their educational status, 309 (51\%) housewives', 200 (33.6\%) had family size > five, $265(44.5 \%)$ of respondents' average monthly family income ranges from 450-1499 Ethiopia Birr (Table1).

Table 1. Sociodemographic characteristics of respondents in Goba town from August1st to 30, southeast Ethiopia, 2013.

\begin{tabular}{|c|c|c|c|}
\hline Variables & Category & Frequency & Percent (\%) \\
\hline \multirow{2}{*}{ Sex } & Male & 41 & 6.9 \\
\hline & Female & 555 & 93.1 \\
\hline \multirow{4}{*}{ Age } & $18-24$ & 172 & 28.9 \\
\hline & $25-34$ & 196 & 32.9 \\
\hline & $35-44$ & 103 & 17.2 \\
\hline & $\geq 45$ & 125 & 21.0 \\
\hline \multirow{3}{*}{ Marital status } & Married & 411 & 69.0 \\
\hline & Single & 151 & 25.3 \\
\hline & Divorced/ Widowed & 34 & 5.7 \\
\hline \multirow{2}{*}{ Religion } & Muslim & 151 & 25.3 \\
\hline & Christian & 445 & 74.7 \\
\hline \multirow{3}{*}{ Ethnicity } & Oromo & 316 & 53.0 \\
\hline & Amhara & 235 & 39.4 \\
\hline & Others & 45 & 7.6 \\
\hline \multirow{5}{*}{$\begin{array}{l}\text { Educational } \\
\text { status }\end{array}$} & Unable to read \& write & 76 & 12.8 \\
\hline & Read and write & 67 & 11.2 \\
\hline & 1-8grade & 124 & 20.8 \\
\hline & 9 -12 grade & 200 & 33.6 \\
\hline & Diploma \& above & 129 & 21.6 \\
\hline \multirow{4}{*}{$\begin{array}{l}\text { Occupational } \\
\text { status }\end{array}$} & Student & 97 & 16.3 \\
\hline & Government employee & 111 & 18.6 \\
\hline & $\begin{array}{l}\text { Private employee/daily } \\
\text { labourer }\end{array}$ & 79 & 13.3 \\
\hline & House wife & 309 & 51.8 \\
\hline \multirow{2}{*}{ Family size } & $\leq 5$ family & 396 & 66.4 \\
\hline & $>5$ family & 200 & 33.6 \\
\hline Monthly & $<450$ & 153 & 25.7 \\
\hline household & $450-1499$ & 265 & 44.4 \\
\hline income & $\geq 1500$ & 178 & 29.9 \\
\hline
\end{tabular}

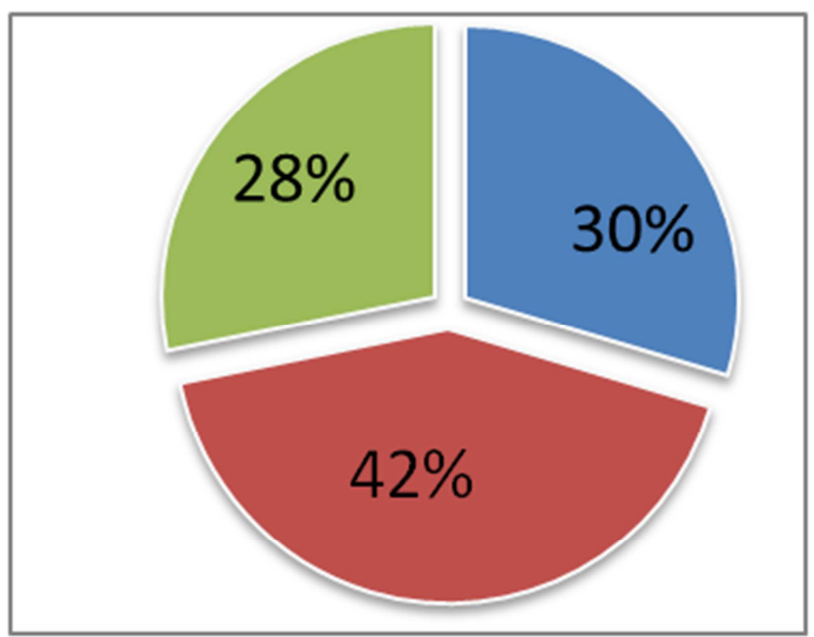

\subsection{Coverage of Adequately Iodized Salt at Household Level}

Coverage of adequately iodized salt $(\geq 15 \mathrm{ppm})$ was found in $179(30 \%)$ households tested for salt samples, 248 (28\%) of the households' salt samples had no iodine at all. The rest 169 (42\%) of the households' salt samples had inadequate iodized salt. For the purpose of this research, the iodine levels of the salt sample were grouped in to two categories namely: adequately iodized salt $(\geq 15 \mathrm{ppm}) \&$ inadequately iodized salt $(<15 \mathrm{ppm})$

Before testing salt samples, $404(67.8 \%)$ of the respondents said they used iodized salt \& 192 (32.2\%) of the respondents said they didn't use iodized salt. From those who used Iodized salt, majority $179 \quad(44.3 \%)$ had got from big shops/supermarkets \& $115(28.5 \%)$ from markets \& the rest from small shops (27.2\%). However; after testing salt samples using rapid test kits, among those who said they used iodized salt, 144 (35.6\%) had adequately iodized salt. But from those who said they used iodized salt, $157(81.8 \%)$ salt sample showed inadequately iodized salt \& 35 (18.2\%) showed adequately iodized salt.

During interview they were asked if they ever heard about iodized salt, $352(59 \%)$ of respondents heard from different sources. Out of those, 119 (33.8\%), $113(32.1 \%) \& 120$ $(34.1 \%)$ of the participants had got the information from health extension workers, school, radio \& television (media) respectively. Knowledge of participants about the usefulness iodized salt \& consequence of IDDs, 182 (51.7\%) of the respondents had sufficient knowledge about iodized salt \& iodine deficiency disorders. Regarding storage place, 450 (75.5\%) of the respondents reported that they stored salt in a dry place away from humid/ fire area.

While $246(41.3 \%)$ of the respondents exposed salt to sunlight when it becomes humid. Concerning washing practice, $62(10.4 \%)$ of respondents reported that they washed salt to remove impurities. Regarding the time when the salt is added during cooking, 341 (57.2) of respondents reported that they add salt at the end of cooking just before the dish is out of fire (Table 2).

Figure 1. Iodine content of iodized salt in Goba town, Bale zone, ONRS, Ethiopia, 2013. 
Table 2. Response of study participants about related factors to availability of Adequately Iodized salt at household level in Goba town, Bale zone, Southeast Ethiopia, 2013.

\begin{tabular}{llll}
\hline Variables & Category & Frequency & Percent \\
\hline \multirow{2}{*}{ Knowledge about iodized salt \& Iodine deficiency disorders } & Insufficient knowledge & 170 & 48.3 \\
& sufficient knowledge & 182 & 51.7 \\
& Unfavourable attitude & 248 & 41.6 \\
Attitude towards iodized salt \&Iodine deficiency disorders & Favourable attitude & 348 & 58.4 \\
& Expensive & 368 & 61.7 \\
Perceived price about Iodized salt & Cheap & 228 & 38.3 \\
& Yes & 62 & 10.4 \\
Washing salt before consumption & No & 534 & 89.6 \\
& Yes & 246 & 41.3 \\
Expose salt to sun light & No & 350 & 58.7 \\
& $\leq 2$ months & 474 & 79.5 \\
Duration of salt storage at home & $>2$ months & 122 & 20.5 \\
& early at the beginning of cooking & 91 & 15.3 \\
Time of adding salt during cooking of food & at the middle during cooking & 164 & 27.5 \\
\end{tabular}

\subsection{Factors Associated with Coverage of Adequately Iodized Salt at Household Level}

The investigation on the presence of association between associated factors and coverage of adequately iodized salt revealed the following results: Having family size greater than five, storing in a dry place, purchasing from supermarket or big shops \& using cover for salt containers, storing salt at home for less than 2 months, not exposing to sunlight, not washing before consumption \& perceived price were significantly associated variables with coverage of adequately iodized salt at household level during univariate analysis.

But, only purchasing from big shops or supermarkets, not exposed to sun light $\&$ perceived cheap were significantly associated with coverage of adequately iodized salt at household level in multivariate analysis. Regarding source of purchase, those who purchased iodized salt from big shops or supermarkets were 1.91 times more likely to have adequately iodized salt at household level than those who purchased from small shops \& market (AOR $=1.91,95 \%$ CI $(1.10,3.34)$ )

Regarding exposure to sun light those who did not expose to sunlight were 2.20 times more likely to have adequately iodized salt at household level than those who exposed to sun light $(\mathrm{AOR}=2.20,95 \% \mathrm{CI}(1.31,3.60))$. Regarding perceived price of iodized salt those who perceived iodized salt as cheap were 1.70 times more likely to have adequately iodized salt at household level than those who perceived it expensive (AOR $=1.70,95 \%$ CI $(1.10,2.60)$ ) (Table 3).

Table 3. Factors associated with coverage of adequately iodized salt in Goba Town, Bale zone, South East Ethiopia, 2013.

\begin{tabular}{|c|c|c|c|c|c|}
\hline \multirow{2}{*}{ Variables } & \multirow{2}{*}{ Category } & \multicolumn{2}{|c|}{ Iodine level } & \multirow{2}{*}{ COR $(95 \%$ CI $)$} & \multirow{2}{*}{$\operatorname{AOR}(95 \% C I)$} \\
\hline & & $<15 p p m$ & $\geq 15 p p m$ & & \\
\hline \multirow{2}{*}{ Family size } & $\leq 5$ & 284 & 112 & 1.00 & 1.00 \\
\hline & $>5$ & 133 & 67 & $1.28(0.89,1.84)$ & $1.11(0.70,1.74)$ \\
\hline \multirow[t]{3}{*}{ Source of purchase } & Small shop & 83 & 27 & 1.00 & 1.00 \\
\hline & Big shop/supermarket & 100 & 79 & $2.43(1.44,4.11)$ & $1.91(1.1,3.34)^{*}$ \\
\hline & Market & 77 & 38 & $1.52(0.847,2.7)$ & $1.23(0.67,2.30)$ \\
\hline Use cover for salt containers & No & 77 & 18 & 1.00 & 1.00 \\
\hline \multirow{2}{*}{ Duration of storage at home } & $>2$ months & 94 & 28 & 1.00 & 1.00 \\
\hline & $\leq 2 \mathrm{months}$ & 325 & 151 & $1.56(0.987,2.5)$ & $1.45(0.77,2.75)$ \\
\hline \multirow{2}{*}{ Expose to sun light } & Yes & 195 & 51 & 1.00 & 1.00 \\
\hline & No & 222 & 128 & $2.21(1.51,3.22)$ & $2.20(1.31,3.60)^{*}$ \\
\hline \multirow{2}{*}{ Perceived price } & Expensive & 271 & 97 & 1.00 & 1.00 \\
\hline & Cheap & 146 & 82 & $1.57(1.10,2.24)$ & $1.70(1.1,2.60)^{*}$ \\
\hline Washing salt & Yes & 51 & 11 & 1.00 & 1.00 \\
\hline Storage place & Dry place & 299 & 151 & $2.13(1.35,3.36)$ & $1.17(0.55,2.4)$ \\
\hline
\end{tabular}

*Significantly associated in multivariate logistic regression at $\mathrm{p} \leq 0.05$ (Enter method).

\section{Discussion}

This study revealed that only $30 \%$ of the households in Goba town were covered by adequately iodized salt $(\geq 15 \mathrm{ppm})$ which was very low compared to study conducted among 8 states of India (51\%), Lucknow district of India (64.2\%), \&
West Bengal (73\%) district of India [11-13]. In Cameron, Kenya, Rwanda, Zimbabwe, Lesotho \& Tanzania households were consuming $85-92 \%$ of adequately iodized salt, this might be due to availability \& accessibility of iodized salt in the market, legislation \& policies to fortify salt with iodine, regular follow up \& monitoring regarding utilization of 
iodized salt in these countries. Compared to these countries the study area had low coverage of adequately iodized salt $(30 \%)$, but better than Sudan (1\%), Niger (15\%), Senegal (16\%), Pakistan (17\%), Afghanistan (28\%) [19]. The finding was also slightly high when compared to National nutrition baseline survey of Ethiopia 2009 (5\%), EDHS 2011 report of the national coverage of iodized salt in Ethiopian 15.4\% \& Oromia region 17.4\%, Bahirdar (24.9\%), Gondar (28.9\%) [10 $21,22]$. This difference might be study area difference as EDHS were conducted both in urban \& rural setting but this study conducted in urban setting. Since Urban dwellers are expected to use iodized salt compared to rural dwellers as data from EDHS 2011 report.

Regarding factors associated with coverage of adequately iodized salt, not exposing to sunlight was associated with the coverage of adequately iodized salt at household level. Findings from qualitative study also showed that salt samples from households not exposing to sun light were found to have adequately iodized salt compared to households exposing salt to sun light. Study conducted in New Delhi documented that there was about $31 \%$ of loss iodine from iodized salt when exposed to sun light [26]. Similar study conducted in London also revealed that exposure to sunlight was associated with loss of iodine level of salt due to the volatile nature of iodine content from salt by heat [27]. Similar study done in Kazakhstan revealed that iodine from iodized salt losses its content gradually when exposed to sun light [28]. Study conducted in Gondar town also revealed that not exposing to sun light was significantly associated with the availability of adequately iodized salt at household [23].

Purchasing from big shop/supermarkets were associated with the coverage of adequately iodized salt at household level, this might be due to proper storage practice in the supermarket than in market \& small shop. Findings from qualitative study also showed that being purchased from supermarkets /big shops found to have adequately covered iodized salt compared to salt from small shops \& markets. Study done in Gondar town showed that from households whose salt samples tested to have adequately iodized salt, majority of them had got iodized salt from supermarkets [23].

Households who perceived iodized salt as cheap were more likely to have adequately iodized salt at household level as they might be more likely to afford to buy iodized salt than households who perceived it expensive. As this might be due to difference on socio economic status. Findings from qualitative study showed that the major reasons for not using iodized salt by the households were the price of iodized salt which was expensive compared to ordinary salt. Few respondents mentioned that reasons for using iodized salt were it is finer in size, easily dissolved \& palatable. This finding is similar for the study conducted in Cambodia found that reasons for using refined salt were "already refined ", easy to dissolve $\&$ good to add in a soup \& saltier than coarse salt $\&$ also majority of the respondents added salt at beginning during cooking of food [29]. Improper practice (i.e. Washing salt before consumption would reduce potential iodine added to the salt) among respondents identified as a major problem for inadequate availability of iodized salt at household level which was similar for study conducted in Haiti that most Haitians wash salt before consumption to remove debris \& impurities [30].

\section{Limitation of the Study}

This study used rapid field testing kit to determine availability of adequately iodized salt from salt samples which did not include titration level of iodine \& urinary iodine concentration testing of iodine to determine body iodine level.

\section{Conclusion \& Recommendations}

The proportion of households covered by adequately iodized salt in Goba town was very low (30\%) compared to the internationally recommended value to control IDD $(90 \%$ $\&$ above). Perceived cheap in price, not exposing to sun light $\&$ being purchased from big shop or supermarket were factors significantly associated with availability of adequately iodized salt at household level in Goba town. Households should be educated about proper handling of iodized salt at household level to achieve universal salt iodization by Goba town health office.

\section{Authors' Contribution}

AK: Study design, data collection \& analyses, interpret the data, draft \& reviewed the manuscript.

\section{Acknowledgements}

We would like to thank UNICEF and Micronutrient Initiative (MI) for their provision of Iodine test kit \& over all orientation on utilization of the iodine test kits.

We would like to acknowledge the Oromia Regional Health Bureau for their cooperation in writing up supportive letter to Bale Zone Health Bureau \& Goba town health office.

My acknowledgement \& appreciation goes to Goba town health office \& Bale zone Health office for their cooperation in facilitating the data collection process.

We would like to acknowledge study participants for their cooperation during data collection.

Lastly, but not the least, we would like to extend my acknowledgement to supervisors \& data collectors for their valuable support during data collection process.

\section{References}

[1] WHO. Global data base on iodine deficiency. Geneva: World Health Organization Department of Nutrition for Health and Development, 2004.1-2. Availableat http://whqlibdoc.who.int/:publications/2004/.

[2] Venkatesh M, John. Salt iodization for the elimination of iodine deficiency,: International Council for Control of Iodine Deficiency Disorders, Netherlands 1995. 1-4. Available at http://www.micronutrient.org. 
[3] WHO, ICCIDD, UNICEF. Assessment of the iodine deficiency disorders and monitoring their elimination. Geneva, 2001: 21-22. Available at http//wwwassessment.monitoring elimination.

[4] WHO, UNICEF, ICCIDD: Assessment of iodine deficiency disorders and monitoring their elimination. A guide for programme managers. $3^{\text {rd }}$ ed. Geneva: 2007: 1718.

[5] Michael Z. key barriers to Global iodine deficiency disorder control a summary report 2007.

[6] Bleichrodt N, Born MP. A Meta analysis of research on iodine and its relationship to cognitive development. Stanbury JB editor. The damaged brain of iodine deficiency, New York, 1994: 195-200.

[7] FMOH, UNICEF. High-Level Salt Iodization Launching and Scale-Up Event, Semera, Afar National Regional State April 2009.

[8] Save the children: Ethiopia national nutrition strategy: Review and Analysis of Progress and Gaps: 2009.

[9] FMOH. National guideline for control and prevention of micronutrient deficiencies: Family Health Department, Addis Ababa, June 2004.

[10] CSA, ICF International. Ethiopia Demographic and Health Survey 2011, Addis Ababa, Ethiopia and Calverton, Maryland, USA 2012.

[11] Sundaresan S, Chandekant S, Pandav. G, Venkatesh M., Galvin M. Summary report iodized salt coverage study across eight states in India, 2010.

[12] Abedi A, Srivastava JP. Consumption of Iodized Salt among Households of Lucknow District (India), International Journal of Advanced Research, 2013: Volume1: 134-139.

[13] Tapas K, Dilip Kumar D, Akhil Bandhu B, Indranil C, Sujishnu M, Rabindranath R. Limited Access to Iodized Salt among the Poor and Disadvantaged in North 24 Parganas District of West Bengal India, Journal of health population \& nutrition, July to August 2010: Vol. 28: 369-374.

[14] Bulliyya G, Mallic G. Prevalence of Iodine Deficiency Disorders among Dongria Kondh Primitive Tribal Community in Niyamgiri Mountain area of Rayagada District (India), Orissa2004-05.

[15] Elizabeth A, Christopher B, Sabah B, Brahim A, Pamela J. Analysis of iodine deficiency disorder \& eradication strategies in the high atlas mountains of morocco, Utah State University, Department of Economics, 1997. Last accessed on 12/11/2013.

[16] Pieter L, Michael J, Carl J. Iodine concentration in household salt in South Africa, Bulletin of the World Health Organization, 2001: v: 79: 534-540.
[17] Sebotsa MLD, Dannhauser A, Mollentze WF, Osthuizen GM, Mahomed FA, Jooste PL. Knowledge, attitudes and practices regarding iodine among patients with hyperthyroidism in the Free State, South Africa Journal of Clinical Nutrition, 2009: v: 22 (1): 18-20.

[18] Buxton C. Baguune B. Knowledge and practices of people in Bia District, Ghana with regard to iodine deficiency disorders and intake of iodized salt. Archives of Public Health 2012.

[19] A2Z. The USAID micronutrient and child blindness project country program experience and results mid project 2005-2008. Accessed on 13/11/2013.

[20] Takele L, Belachew T, Bekele T. Iodine concentration in salt at household and retail shop level in Shebe town, south west Ethiopia. East African Medical Journal 2003: volume 80: $532-540$.

[21] Cherinet A., Yamane B. The goiter rate, its association with reproductive failure, and the knowledge of iodine deficiency disorders among women in Ethiopia, PUBMED, Nov. 2007, 7-316.

[22] Tesheme S. Assessment of knowledge, attitude \& practice of iodized salt consumption and factors associated with iodized salt consumption in BahirDar town 2010, 30-31.

[23] Hailey G, Melkie E, Digsu N. Availability of adequately iodized salt at household level and associated factors in Gondar Town, Northwest Ethiopia: Hindawi Publishing Corporation: 2012.

[24] F. Population Census Commission, "Summary and statistical report of the population and housing census: Population size by age and sex, Addis Ababa 2007.

[25] Demolish H, Gashaw K, Melese A. The Prevalence of Goiter and Its associated Factors among Primary School Children in Goba Town, South East Ethiopia. 2012.

[26] Kapil U, Prakash S, Nayar D. Some factors influencing losses of iodine from iodized salt, Indian Journal of Maternal and Child Health, 1998: vol. 9: 46-7.

[27] Kelly F. Studies on the stability of iodine compounds in iodized salt. Bull. World Hlth Org. 2000: vol. 9: 217-230.

[28] Waszkowiak K, Szymandera B. Effect of storage conditions on potassium iodide stability in iodized table salt and collagen preparations, International Journal of Food Science \& Technology, 2007: vol. 43: 895-899.

[29] Hellen Keller International. Knowledge, attitude, practice about iodized saltin Cambodia. Feb. 1999.

[30] Iodine Network's Advocacy Mission to Haiti: A Call for a National Coalition 2006. 